\title{
Sternal dehiscence
}

\author{
Early detection by radiography
}

A study was conducted to look for radiographic indicators that might provide a clue to threatened separation of the median sternotomy closure. To evaluate this problem, we studied two groups of patients. In group $A$ the postoperative plain chest roentgenograms of 50 consecutive patients having cardiac operations were reviewed until the time of their complete recovery from the operation. Sternal problems were not identified in these patients clinically. However, chest roentgenograms showed that one patient had a displaced sternal wire and another had a classic sternal separation as judged by the change in wire topography. In the second series of patients, group B, 10 patients with clinical separation of the sternum were similarly evaluated. In seven of the 10 an early subtle change in position of one or more sternal wires preceded clinical detection of separation by 1 to 8 days, and a gross change in the sternal wire positions preceded clinical diagnosis in five patients by 1 to 6 days. The appearances of the wires by roentgenogram showed four common patterns. These findings indicate that thoracic surgeons and radiologists alike do not always carefully examine the appearance of the sternal wires on the postoperative roentgenograms. Subtle changes or gross changes in the position of the wires is an indicator of sternal separation. Therefore, the topography of the sternal wires should be scrutinized along with the other postoperative changes seen on roentgenograms after median sternotomy. (J Thorac Cardiovasc Surg 1994;108:616-9)

Ronald H. Hayward, MB, ChB, PhD, Wade L. Knight, MD, Clinton E. Baisden, MD, and Charles G. Reiter, MD, Temple, Tex.

$\mathrm{D}$ ehiscence of the median sternotomy closure is infrequent. It may be latent or difficult to detect clinically, or it may be sudden and very obvious. In reviewing the record of several patients who had had dehiscence, we discovered that surgeons do not consistently examine the position of the sternal wires in their evaluations of postoperative chest films. Yet, although a gross separation may be clearly demonstrated by en bloc displacement of the wires, the early changes are not always appreciated. Likewise, radiologists pay little attention to these wires. Even with gross displacement, radiologists seem to be unaware of the significance of these changes or else

From Texas A\&M University Health Science Center College of Medicine, Scott and White Clinic, Temple, Tex.

Received for publication Oct. 13, 1993.

Accepted for publication Jan. 28, 1994.

Address for reprints: R. H. Hayward, MB, ChB, PhD, 2401 S 31st St., Temple, TX 76508.

Copyright $(1994$ by Mosby-Year Book, Inc.

$0022-5223 / 94 \$ 3.00+0 \quad \mathbf{1 2} / \mathbf{1} / \mathbf{5 5 5 4 8}$ believe that the surgeon will check the wires. Techniques of sternal closure vary, and it is not our purpose to evaluate these. The objective has been to assess the postoperative appearance of the sternal wires on serial plain chest roentgenograms and to determine the early and late changes in their configuration that might suggest impending dehiscence or confirm its presence.

\section{Method of study}

This study concerned patients who had undergone cardiac operations. Two groups were evaluated: The serial postoperative plain chest films of 50 consecutive patients with no recorded sternotomy problem were reviewed retrospectively. They comprised group A. The alignment of the sternal wires was noted as a baseline on the first postoperative film and was compared with subsequent films until the time of full recovery and termination of surgical care. The sternal wires were examined for (1) loss of their original alignment, (2) change in configuration, and (3) a lateral shift of one or more wires in comparison with the others.

In group B, the postoperative chest roentgenograms of 10 patients who had had clinical separation of the sternum were similarly studied. The date of the first subtle change in sternal wire alignment was noted, followed by the sequential changes 

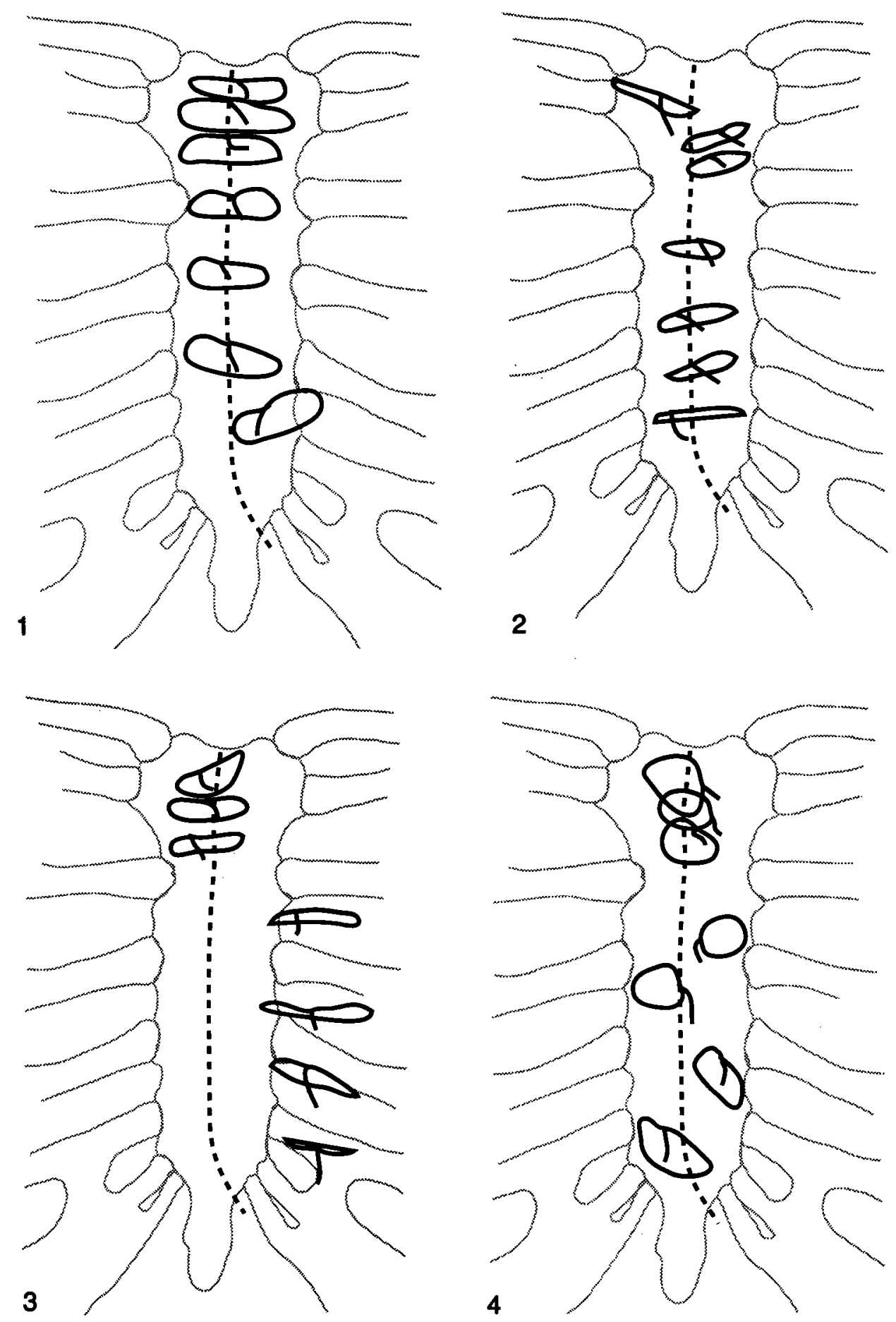

Fig. 1. Early or subtle shift and tilt of wire 7 to the left (type 1).

Fig. 2. Gross changes with wire 1 displaced to the right and wires 2 and 3 to the left (type 2).

Fig. 3. Gross changes with en bloc shift of wires $4,5,6$, and 7 to the left (type 3).

Fig. 4. Late change with all wires rotated and the lower four displaced in a random fashion (scrambled type 4). 


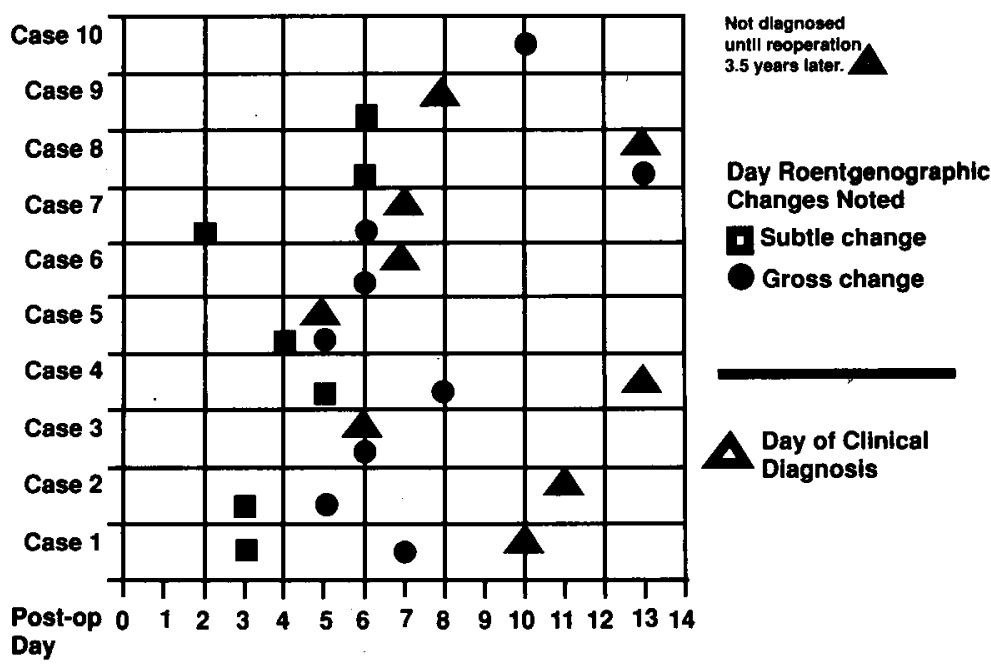

Fig. 5. Postoperative observation of median sternotomy wire displacement indicating day of subtle or gross change and clinical detection. Case 10 showed gross changes on postoperative day 10 , but separation was not diagnosed until seen at reoperation $3 \frac{1}{2}$ years later.

in appearance until the time separation was noted by clinical examination. A record was made of the time interval between the dates of the first subtle wire change, unequivocal displacement, and clinical detection of dehiscence. The patterns of sternal wire displacement were classified as early and subtle (suggesting separation in progress) or late and gross (confirming separation). A search was also made for the midsternal stripe as an indicator of dehiscence. Because projection is very poor in printed photographs of roentgenograms, accurate drawings were made of the sternal wires and superimposed diagrammatically over an intact sternum. The drawings were done primarily to show the wire relationships and do not indicate whether the wires actually circled or penetrated the sternum. Likewise, because the anatomy of the dehiscence is not usually recorded or photographed by the surgeon, the sternum in the diagrams is not represented as separated, except where illustrated as a hypothetical example. Cases of sternal wound infection were excluded.

\section{Results}

In all cases, displacement of wires detected by roentgenography could be described as subtle or gross. Subtle changes comprised an early lateral shift or tilting of one or two wires resulting in loss of the original alignment (type 1, Fig. 1). Gross changes included a bilateral shift or tilt of two or three wires, some to the left and some to the right (type 2, Fig. 2), a dramatic en bloc shift of three or four wires to one side (type 3, Fig. 3), or a random displacement of almost all wires with an associated rotation and opening up of the loops (type 4, Fig. 4). We refer to the latter as "scrambled wires." Films taken at time intervals between the early and late changes often showed steady progression of wire displacement. The midsternal stripe was seen in only two cases.
The review of 50 patients who had an apparently uneventful convalescence (group A) showed two with wire changes. One had a subtle change with the last wire tilted and displaced to the left (type 1), but whether this represented some degree of separation of the lower part of the sternum is unknown. One patient had a missed type 3 sternal dehiscence but had described sternal discomfort for several months after the operation and had recurrent left pleural effusions that necessitated thoracentesis on four separate occasions.

Of the 10 patients who had a definite dehiscence that was repaired surgically (group B), seven had a type 1 roentgenographic change that preceded the clinical detection of separation by 1 to 8 days. Type 2, 3, or 4 changes preceded clinical detection by 1 to 6 days in five patients, and in one instance by $3 \frac{1}{2}$ years (Fig. 5). When the wires were scrambled, the malposition was also obvious on the lateral chest film. Fracture or untwisting of wires was not seen, and only two roentgenograms showed a midsternal stripe. Patient 10 (group B) had a pseudoarthrosis with type 3 wire changes at the time of her second coronary bypass operation $3 \frac{1}{2}$ years after the initial operation. Review of the record revealed an early postoperative history of sternal "popping" and recurrent left pleural effusions, but the separation had not been diagnosed.

\section{Discussion}

In 1977 , Ziter ${ }^{1}$ drew attention to changes in configuration of the sternal wires with separation, but few publications have appeared since that time. Escovitz, Okulski, and Lapayowker ${ }^{2}$ believed that the midsternal stripe 
was a universal indicator of sternal separation. However, Berkow and Demos ${ }^{3}$ believed that it was a fairly infrequent sign. This finding was visible in only two of our 10 patients. It is possible that this separation and stripe may not be detected unless the standard chest roentgenogram is taken absolutely in line with the sternotomy. We believe, therefore, that this sign does not have much merit when routine films are being reviewed. It is apparent that any subtle change in position of a sternal wire should be considered as a warning of possible separation. Gross changes confirm that a separation has occurred. Wire shift in a rotated chest film should not be confused with displacement, because in this case vertical alignment is well maintained. An illustration of the typical bone and wire findings often encountered during repair is depicted in Fig. 6. If a more definitive assessment of the suspected separation is required, a computed tomographic scan is the ultimate study. ${ }^{46}$ These films, however, are not routinely obtained for early detection of dehiscence.

\section{Conclusions}

Wound dehiscence after median sternotomy is often heralded by subtle changes in the roentgenographic position of the sternal wires. It is important for all thoracic surgeons to be aware of these early indicators of separation and to check the plain chest roentgenogram carefully for wire alignment and change in configuration. Diagnosis of separation is then confirmed by clinical evaluation or computed tomographic scan. Radiologists who read postoperative films for surgeons can be of tremendous assistance by reporting these changes along with their routine descriptions of the lung fields. Late sternal discomfort, popping, or pleural effusions require a careful radiographic review and clinical evaluation of the sternum, because bone separation is likely.

\section{REFERENCES}

1. Ziter FMH Jr. Major thoracic dehiscence: radiographic considerations. Radiology 1977;122:587-90.

2. Escovitz ES, Okulski TA, Lapayowker MS. The midsternal stripe: a sign of dehiscence following median sternotomy. Radiology 1976;121:521-4.

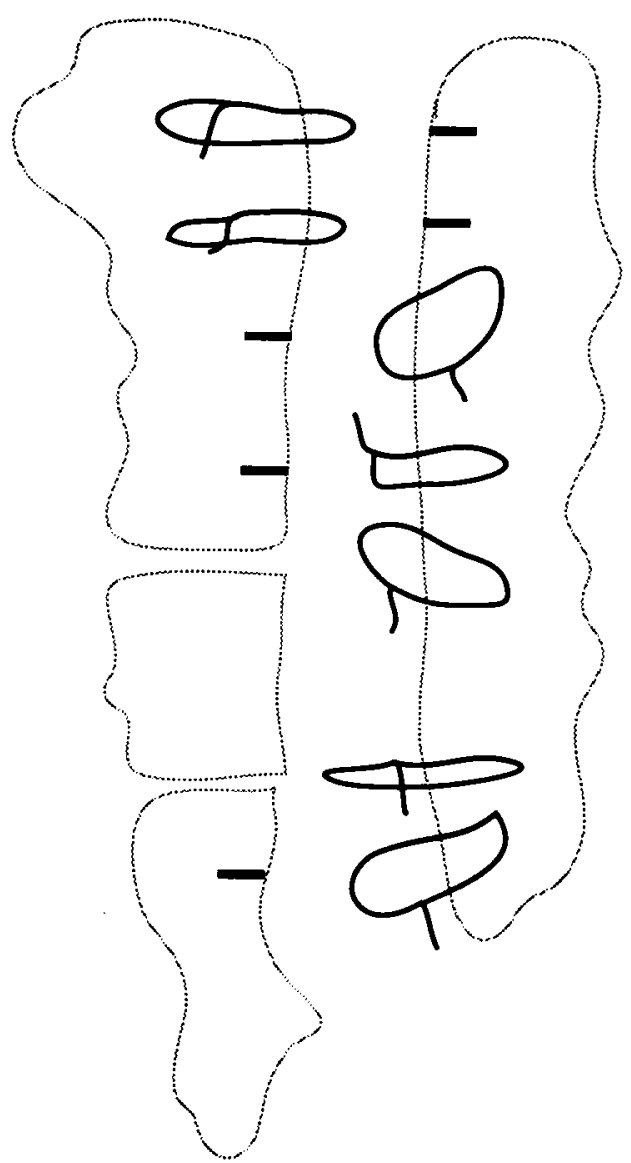

Fig. 6. Hypothetical findings at time of surgical rewiring.

3. Berkow AE, Demos TC. The midsternal stripe and its relationship to postoperative sternal dehiscence. Radiology 1976;121:525.

4. Kay HR, Goodman LR, Teplick SK, Mundth ED. Use of computed tomography to assess mediastinal complications after median sternotomy. Ann Thorac Surg 1983;36:706-14.

5. Vanleeuw P, Roux D, Fournial G, et al. Early postoperative sternal approximation after ITA harvesting: computed tomographic evaluation. Ann Thorac Surg 1991;52:518-22.

6. Templeton PA, Fishman EK. CT evaluation of post sternotomy complications. AJR Am J Roentgenol 1992;159:45-50. 